www.jmscr.igmpublication.org

Index Copernicus Value: 79.54

ISSN (e)-2347-176x ISSN (p) 2455-0450

crossref DOI: https://dx.doi.org/10.18535/jmscr/v7i3.240

\title{
Functional outcome of intra-articular fractures of distal radius using external fixator: A long term study
}

\author{
Authors \\ Dr Manzoor A Halwai, M Iqbal Wani, Hilal Ahmad Kotwal* \\ *Corresponding Author \\ Hilal Ahmad Kotwal
}

Post Graduate Department of Orthopedics BJS Hospital Barzulla GMC Srinagar 190005, India

\begin{abstract}
Communited intra-articular fractures of distal end of radius always poses a challenge to the treating surgeon. Inability to achieve and maintain near anatomic restoration of the fracture can cause instability, pain and reduced function. This study reported the results retrospectively of the use of standard protocol of closed reduction and external fixation of these fractures.

Methods: the study contains the 50 patients who underwent closed reduction and external fixation with or without augmentation with $k$-wires. Thirty three patients required additional $k$-wires. The mean time of fixator removal was seven weeks.

Study Design: observational prospective study at tertiary care hospital from September 2013 to august 2016.

Results: At mean of 24 months postoperatively, the mean arc of flexion-extension was 89\% of that of uninjured side and mean grip strength was $90 \%$ of that of uninjured side. The mean articular step-off was $1 \mathrm{~mm}$ and the radial length was restored to $12 \mathrm{~mm}$. according to the modified Green and O'Brein rating system, 27 patients had a good or excellent result.

Keywords: distal radius, external fixator, communited, ligamentotaxis, fracture.
\end{abstract}

\section{Introduction}

With a share of $25 \%$, fractures of the distal radius are counted among the most frequent fractures in adults ${ }^{1}$. Distal end fractures form one sixth of fractures treated in emergency department ${ }^{2}$. The incidence of this injury appears to be both gender and age specific. There are three main peaks of fracture distribution: one in children age 5-14, the second in males under age 50, and the third in females over the age of 40 years. Overall incidence rates about 24-27 per 10,000 persons/ year have been reported ${ }^{3}$. There is a female dominance in the occurrence of fractures of the distal radius. The female-male ratio is about $3: 1^{4}$. There is no gender predominance under the age of 40 years, and incidence rates of about 10-15 per 10,000 persons have been reported. After the age of 40 years, the incidence rate increases rapidly in women who then outnumber men. At the age of 50 years, women have a life-time risk of $17 \%$ compared with only $3 \%$ in men ${ }^{5}$. Restoration of congruity of the articular surface is the most critical factor for a good functional result. 2-8 Restoration of radial length (the distance from the 
radial styloid process to the distal head of the ulna), radial tilt angle, and volar tilt angle is also important $^{6,7}$. Failure to achieve and maintain nearly anatomicrestoration can lead to degenerative arthritis, distal radioulnar and midcarpal in stability, and ulnar impaction syndrome, with resultant pain, decreased motion and strength, and poorfunction.

External fixator is based on ligamentotaxis ${ }^{8}$, in which the fracture fragments are moulded by traction forces across the ligaments. External fixation is unable to prevent dorsal collapse of the radius or maintain the normal palmar tilt of the radiocarpal joint surface. This complication may predispose to post-traumatic wrist instability and arthritis.

We report the results of a prospective study of the use of closed reduction and external fixation of intra-articular fractures in fifty patients who were followed for a minimum of two years.

\section{Materials and Methods}

This study was conducted in Government Hospital for Bone and Joint Surgery, Postgraduate Department of Orthopaedics, Government Medical College, Srinagar Kashmir from September 2013 to august 2016. The study was approved by the College Research Ethics Committee. This prospective randomized observational study consisted 30 cases who underwent ligmentotaxis with external fixation. Patients included in the study were adults (Age 20 -60), patient with intra articular fractures of distal end of radius ( $\mathrm{AO}$ Type $\mathrm{B} / \mathrm{C}$ ), all closed and Grade I (Gustillo and Anderson) compound fractures and presenting within 72 hours of injury. Patients with Grade II and III open fracture distal radius, pathological fractures, rheumatoid arthritis, concomitant injuries of same limb, bilateral distal end radius fractures and neurovascular injuries were excluded. The specific radiographic criterion for considering closed reduction as acceptable was more than a 2- mm step-off of the distal articular surface of the radius, The fractures were assessed preoperatively by wrist radiographs (PA and
LATERAL) and were classified according to the AO/ASIF classification system. Seven patients (14\%) had 23.B2 type of fracture, seventeen patients (34\%) had 23.B3 type of fracture, ten patients (20\%) had 23.C1, eight patients (16\%) had 23.C2 type of fracture and eight patients (16\%) had 23.C3 type of fracture. Demographic Data The fifty patients who were included in the study consisted of twenty-nine men and twentyone women who ranged in age from eighteen to fifty nine years (mean, thirty-eight years). Thirty patients presented initially at our institution, and twenty was referred secondarily. The dominant wrist was injured in 28 patients and the non dominant wrist, in 22 . The initial injury resulted from a high-energy mechanism in forty patients: fifteen were injured in a fall from a height; while as twenty-five had injury during a road traffic accident. The injury resulted from a lower-energy mechanism in ten patients: seven fell while walking or running, three were injured while doing household activity.

\section{Operative Technique ${ }^{9}$}

The patient was placed supine on operation table. intravenous antibiotics were used before the start of procedure. Thorough scrubbing was done and part painted with betadine and then draped. The limb was placed on sideboard. The limb was placed on sideboard with limb abducted $90^{\circ}$ at shoulder and elbow and forearm pronated.

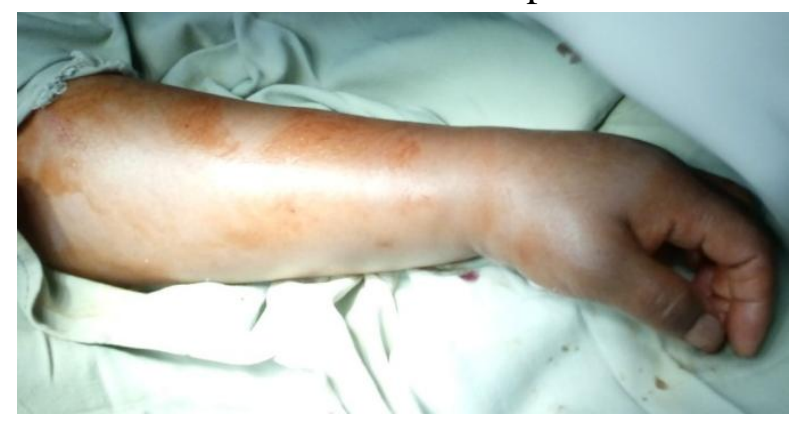

Figure 1 Position of the Limb

Under C arm control, preliminary close reduction of fracture was carried out. A longitudinal stab incision was made over the dorso-lateral of the radius, proximal to the muscle bellies of APL and EPB and between the bellies of EDC and Ecrl/ecrb followed by blunt dissection. The 


\section{JMSCR Vol||07||Issue||03||Page 1437-1443||March}

proximal pin was then inserted engaging both cortices of the radius at an angle of $30-40^{\circ}$ with respect to saggital plane, as shown in figure $2 \mathrm{~A}$. Distal pin was inserted proximal to the transition

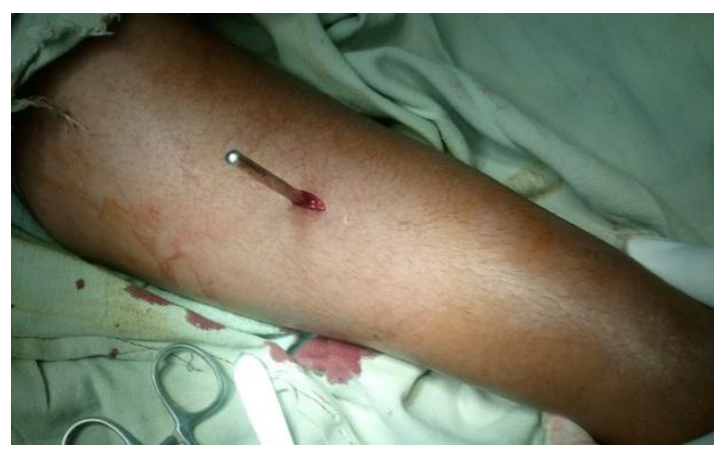

Figure 2 A) Proximal pin placement

In order to avoid transfixing the extensor tendon hood the $1^{\text {st }}$ metacarpophalangeal joint was passively flexed to $90^{\circ}$ so that extensor tendon hood moves slightly distally and the tendons are

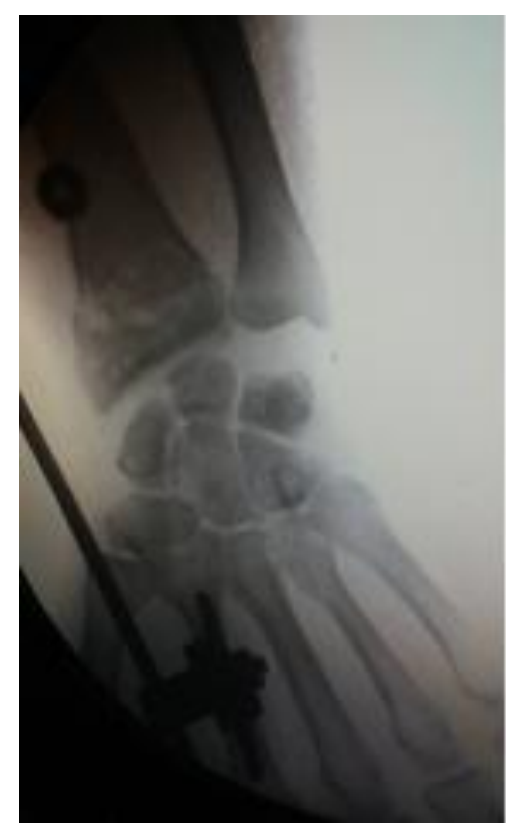

Figure 3 Reduction Checked Under C-ARM

The distal radial pin was then placed as close to the fracture site as possible with angle of $30-40^{\circ}$ with respect to saggital plane. The proximal pin was placed in the $2^{\text {nd }}$ meta carpal distal to transition of shaft into the metacarpal base angle of $2^{\text {nd }}$ metacarpal head into the shaft of the $2^{\text {nd }}$ metacarpal. The pin was then inserted engaging both cortices of the $2^{\text {nd }}$ metacarpal at an angle of $30-40^{\circ}$ with respect to saggital plane.

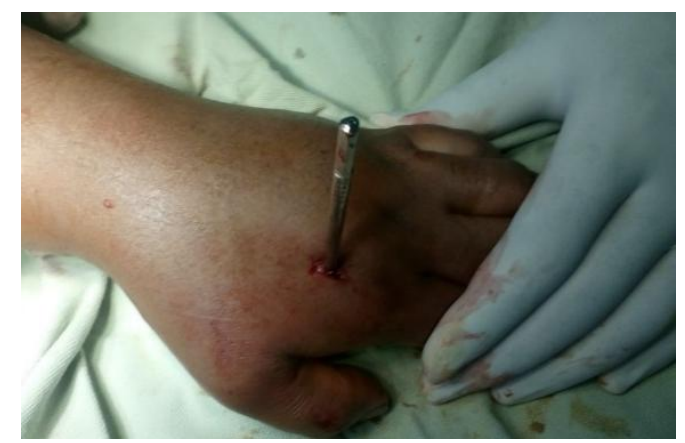

B) Distal pin placement

pulled in an ulnar direction ${ }^{67}$ as shown in figure 2 B. The fixator was assembled but not tightened. Reduction of the fracture was then achieved and checked under C-ARM as shown in figure 3.

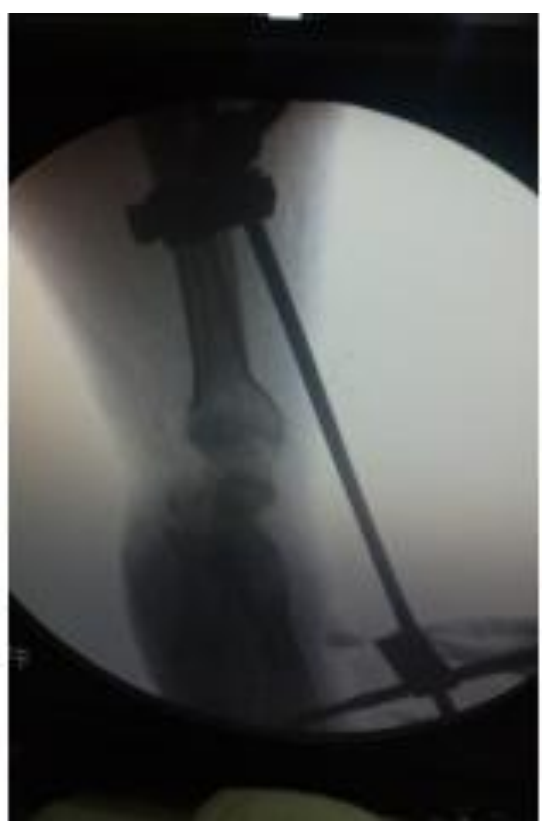

of $30-40^{\circ}$ with respect to saggital plane ${ }^{65}$. Both pins were connected to the fixator rod. Whole assembly was tightened final reduction and pin sizes were checked under C-ARM. 


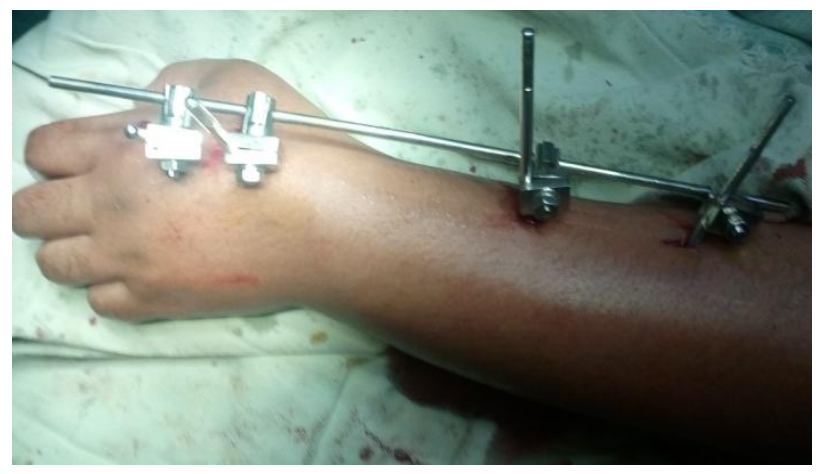

Figure 4 final assembly

Pin sites were dressed.

\section{Post Operative Care \& Rehablitation ${ }^{10,11,12}$}

Immediate post-operative check X-rays were taken both PA and lateral views. Active movements of all fingers and elbow were carried out on $1^{\text {st }}$ post-operative day and continued thereafter. The patients were called for inspection and dressing change at the end of $2^{\text {nd }}, 4^{\text {th }} \& 6^{\text {th }}$ weeks. The external fixator was removed on the 7th week. Check X-ray was taken in both PA and lateral view. The range of motion at the wrist was recorded and any deformity was assessed. Patients underwent physiotherapy regularly. All the cases were followed monthly, at 6 months and final follow up at 2 years.

Follow-up Assessment Fracture: Classification Fracture classification: Fractures were categorized on preoperative radiographs (without traction or computed tomographic scans) within the $\mathrm{AO}$ classification. intra articular TypeB/C fractures, the most severe within the AO system, are divided into three sub classifications according to whether the comminution

Objective Assessment: At the final follow-up examination, patients were tested for range of motion, for grip strength with a hand held dynamometer. Measurements of the contra lateral side served as controls. Subjective Assessment: At third, sixth month and at final follow-up visit at 2 years, a quick dash questionnaire was given and the scoring was done and recorded. Assessment of Radiographic Parameters: Standard guidelines were utilized to determine selected radiographic parameters, 23,24 which were analysed on posteroanterior and lateral radiographs made at fiver time points: preoperatively before any reduction manoeuvres, immediately after the operation, at third months, at sixth month and at the final follow-up at 2 years evaluation. Values for the contra lateral side were determined from posterioanterior and lateral radiographs made at the final follow-up examination.

\section{Results}

1)Age

The mean age was 38.28 years

Table 1 Sex distribution

\begin{tabular}{|l|c|c|}
\hline & NO.OF PATIENTS & PERCENTAGE \\
\hline MALE & 20 & 40 \\
\hline FEMALE & 30 & 60 \\
\hline TOTAL & 50 & 100 \\
\hline
\end{tabular}

Table 2 Side Distribution

\begin{tabular}{|l|c|c|}
\hline GROUP & RIGHT & LEFT \\
\hline & $21(43.30 \%)$ & $29(56.70 \%)$ \\
\hline
\end{tabular}

Table 4 Dominant Side Distribution

\begin{tabular}{|l|c|}
\hline RIGHT(DOMINANT) & $\begin{array}{c}\text { LEFT(NON } \\
\text { DOMINANT) }\end{array}$ \\
\hline $25(50 \%)$ & $25(50 \%)$ \\
\hline
\end{tabular}

MODE OF INJURY: The distribution of mode of injury in our study is given in the following table. The road traffic accidents (RTA), fall on outstretched hand (FOSH) and fall from height (FFH) were the different modes of injury.

Table 5 Mode of Injury

\begin{tabular}{|l|c|c|}
\hline RTA & FOSH & FFH \\
\hline $25(50 \%)$ & $10(20 \%)$ & $15(30 \%)$ \\
\hline
\end{tabular}

Average time taken for radiological union was $15( \pm 3.23)$ WEEKS

The mean range of motion six months and at final follow up was as follows

Table 6

\begin{tabular}{|l|c|c|}
\hline Range of motion & $\begin{array}{c}6 \text { months } \\
\text { (Degrees) }\end{array}$ & $\begin{array}{c}2 \text { years } \\
\text { (Degrees) }\end{array}$ \\
\hline Dorsiflexion & 69.8 & 72.5 \\
\hline Palmerflexion & 63.1 & 69.3 \\
\hline Ulner deviation & 35 & 27 \\
\hline Radial deviation & 11.87 & 12 \\
\hline Supination & 70 & 78 \\
\hline Pronation & 77 & 82 \\
\hline
\end{tabular}


The radiological parameters are shown in the following table

\section{Table 7}

\begin{tabular}{|l|c|c|}
\hline $\begin{array}{l}\text { RADIAL } \\
\text { HEIGHT(MM) }\end{array}$ & VOLAR TILT $\left({ }^{0}\right)$ & $\begin{array}{c}\text { RADIAL } \\
\text { INCLINATION }\left({ }^{0}\right)\end{array}$ \\
\hline $6 \pm 1.79$ & $8.73 \pm 4$ & $16.81 \pm 6.1$ \\
\hline
\end{tabular}

Grip Strenght: Mean grip strength at final follow up was $90 \%$ of the opposite side.

Table 8

\begin{tabular}{|l|c|c|c|c|}
\hline $60-70$ & $71-80$ & $81-90$ & $91-100$ & MEAN \\
\hline $4(13 \%)$ & $03(10 \%)$ & $27(90 \%)$ & O & $90 \%$ \\
\hline
\end{tabular}

Table 9 Functional Outcome at Final Follow-up Visit

\begin{tabular}{|l|c|c|c|}
\hline PARAMETERS & $\begin{array}{c}\text { INJURED } \\
\text { WRIST }\end{array}$ & $\begin{array}{c}\text { INJURED } \\
\text { WRIST }\end{array}$ & $\begin{array}{c}\% \text { OF INURED } \\
\text { SIDE VS } \\
\text { UNJURED } \\
\text { SIDE }\end{array}$ \\
\hline EXTENSION & $68^{\circ} \pm 10^{\circ}$ & $75^{\circ} \pm 13^{\circ}$ & $90 \%$ \\
\hline FLEXION & $69^{\circ} \pm 8^{\circ}$ & $75^{\circ} \pm 8^{\circ}$ & $92 \%$ \\
\hline $\begin{array}{l}\text { ARC OF FLEXION } \\
\text { EXT. }\end{array}$ & $\begin{array}{c}134^{\circ} \pm \\
22^{\circ}\end{array}$ & $\begin{array}{c}148^{\circ} \pm \\
21^{\circ}\end{array}$ & $90.5 \%$ \\
\hline SUPINATION & $78^{\circ} \pm 15^{\circ}$ & $86^{\circ} \pm 7^{\circ}$ & $90 . \%$ \\
\hline PRONATION OF & $86^{\circ} \pm 6^{\circ}$ & $89^{\circ} \pm 15^{\circ}$ & $96.6 \%$ \\
\hline $\begin{array}{l}\text { ARC } \\
\text { PRONATION } \\
\text { SUPINATION }\end{array}$ & $21^{\circ}$ & $174^{\circ} \pm$ & $96.5 \%$ \\
\hline $\begin{array}{l}\text { RADIAL } \\
\text { DEVIATION }\end{array}$ & $24^{\circ} \pm 6^{\circ}$ & $32^{\circ} \pm 7^{\circ}$ & $75 \%$ \\
\hline $\begin{array}{l}\text { ULNAR } \\
\text { DEVIATION }\end{array}$ & $38^{\circ} \pm 6^{\circ}$ & $45^{\circ} \pm 8^{\circ}$ & $84.44 \%$ \\
\hline $\begin{array}{l}\text { ARC OF } \\
\text { RADIOULNAR } \\
\text { DEVIATION }\end{array}$ & $62^{\circ} \pm 11^{\circ}$ & $77^{\circ} \pm 13^{\circ}$ & $80.5 \%$ \\
\hline GRIP STRENTH & $42 \pm 6 \mathrm{~kg}$ & $47 \pm 7 \mathrm{~kg}$ & $89.3 \%$ \\
\hline
\end{tabular}

Quick dash Score: The final functional outcome was evaluated using quick dash score. The result at 6 months follow up was $10.92 \pm 8$ at final follow up at 2 years, it improved to $8.76 \pm 7$

\section{Discussion}

The findings of our retrospective study confirm the observation by others that anatomic restoration of the articular surface is a critical part of the operative treatment of intra-articular fractures of distal radius and has a direct influence on the final outcome. ${ }^{13,14,15,16}$ Bradway et al. and Knirk and Jupiter showed that $>2 \mathrm{~mm}$ of articular incongruity (step-off) was associated with a high prevalence of post-traumatic arthritis and poorer functional results. The treatment of distal radius fractures has undergone changes owing to the advances in technology. Improved imaging methods providing better understanding of fractures and elucidation of the effects of injury type on fracture formation and factors leading to instability have given way to new fixing methods and materials appropriate for the fracture. Distal radius is important in the kinematics of radiocarpal and radioulnar joints. Hence, anatomical reduction of the articular surface, stable fixation, restoration of the radial length, volar angulation and radial inclination are the prerequisite for good clinical outcome. All this reduces the incidence of post-traumatic osteoarthritis and allow early functional rehabilitation $^{17}$

The use of an external fixator alone or in conjunction with percutaneous or limited internal fixation, for unstable fractures of the distal end of the radius has produced good or excellent results. We attribute to these good or excellent results to the early removal of the fixator that allows early range-of-motion exercises and to avoid complications commonly associated with the prolonged use of external fixators ${ }^{18}$. We believe that intra-articular (AO type-B/C) fractures of the distal part of the radius can be treated by closed reduction and external fixation. Our series demonstrates that this technique, supplemented by k-wires as needed, is a satisfactory treatment that can lead to a high rate of return to work and sports, a high level of patient satisfaction, and a low rate of complications.

Outcome of Evaluations with Clinical Rating Systems According to the modified clinical scoring system of Green and O'Brien ${ }^{19}$, the functional result was excellent for 2 patient and good for six, the result was fair for eight patients and poor for 3. The mean score (and standard deviation) was $72.5 \pm 17.3$ points (range, 25 to 90 points). The mean pain score was 23 points (range, 0to 25 points), and the mean return-towork score was 21 points (range, 0 to 25 points). The quick dash score at the final follow up was 
$8.76 \pm 7$. The findings of our retrospective study confirm the observation by others that anatomic restoration of the articular surface is a critical part of the operative treatment of intra-articular fractures of distal radius and has a direct influence on the final outcome. Bradway et al.19 and Knirk and Jupiter showed that $>2 \mathrm{~mm}$ of articular incongruity (step-off) was associated with a high prevalence of post-traumatic arthritis and poorer functional results. The treatment of distal radius fractures has undergone changes owing to the advances in technology. Improved imaging methods providing better understanding of fractures and elucidation of the effects of injury type on fracture formation and factors leading to instability have given way to new fixing methods and materials appropriate for the fracture. Distal radius is important in the kinematics of radiocarpal and radioulnar joints. Hence, anatomical reduction of the articular surface, stable fixation, restoration of the radial length, volar angulation and radial inclination are the prerequisite for good clinical outcome. All this reduces the incidence of post-traumatic osteoarthritis and allow early functional rehabilitation. The degree of disability after distal end radius fracture has been seen to correlate with the amount of residual deformity. Treatment options include closed reduction and pinning, bridging and non-bridging external fixation and open reduction with dynamic compression plate (DCP), precontoured locking and non locking plates and screw fixation through a variety of approaches $^{20}$. Failure to reduce intra-articular fractures of the distal radius predisposes to pain, restricted movement and degenerative arthritis. Malposition is related to the radial height, radial angle, volar tilt and the accuracy of intra-articular reduction. In the treatment of comminuted distal radius intra articular fractures, surgeons may encounter serious complications such as difficult reduction and stabilization, loss of reduction, limitation of range of movement, post traumatic arthritis of the wrist. A brief classification should be made before treating the distal radial fractures.
Among various classification systems, the AO classification system is the most suitable one because it reflects the severity of the fracture and helps the surgeon and the patient to know the possible outcomes. The use of an external fixator alone or in conjunction with percutaneous or limited internal fixation, for unstable fractures of the distal end of the radius has produced good or excellent results. We attribute to these good or excellent results to the early removal of the fixator that allows early range-of-motion exercises and to avoid complications commonly associated with the prolonged use of external fixators.

\section{Conclusion}

We believe that intra-articular (AO type-B/C) fractures of the distal part of the radius can be treated by closed reduction and external fixation. Our series demonstrates that this technique, supplemented by k-wires as needed, is a satisfactory treatment that can lead to a high rate of return to work and sports, a high level of patient satisfaction, and a low rate of complications

\section{Bibliography}

1. David S. Ruch, Rockwood \& Green's, USA, Lippincott: Williams \& Wilkins, chapter 26, 910 pp.

2. Reynolds, Paul R., Beredjiklian, Pedro K. Hand and wrist. Volume 12(4),Lippincott USA: Williams \& Wilkins, 286-289 pp. August 2001.

3. KK Wong, KW Chan. Volar fixation of dorsally displaced distal radia lfracture using locking compression plate. Journal of Orthopaedic Surgery 2005;13(2):153-157 pp.

4. Chen Kai, Yang Chang, Wang Qiu-gen. Applied principles and cautions of locking compression plate, Shangai. Journal of clinical rehabilitative tissue engineering research April 2008; $12: 22$.

5. Santiago A, Lozano-Calderon. New technologies for the treatment of trauma 
sequelae in elderly patients. The orthopaedic journal at Harvard Medical Sciences 2005; 1: $1-8$.

6. Cooney WP. Fractures of the distal radius. A modern treatment based classification. Orthop Clin North Am 1993 ; 24 : 211-16

7. Cooney WP, Dobyns JH, Linscheid R. Complications of Colle's Fractures JBone Joint Surg [Am] 1980 ; 62-A (4) : 613-19.

8. Gartland J J, WERLEY C W , (1951) Evauluation of healed colles fractures. JBJS. 33A. 849-907

9. Surgical Treatment of Distal Radial Fractures with a Volar Locking Plate Versus Conventional Percutaneous Methods A Randomized Controlled Trial Alexia Karantana, Nicholas D. Downing, Daren P. Forward, DM, Mark Hatton, FRCS(Orth), Andrew M. Taylor, Brigitte E. Scammell, Chris G. Moran, and Tim R.C. Davis. J Bone Joint Surg Am. 2013;95:1737-44

10. Internal versus external fixation for unstable distal radius fractures: an up-to-date metaanalysis Zhuang Cui \& Jianhong Pan \& Bin $\mathrm{Yu} \&$ Kairui Zhang \&Xiaolong XiongInternational Orthopaedics (SICOT) (2011) 35:1333-1341

11. Prospective Randomised Study of IntraArticular Fractures of the Distal Radius Comparison Between External Fixation and Plate Fixation. Germaine GQ Xu, Siew Pang Chan,Mark Edward Puhaindran, Winston YC Chew.Ann Acad Med Singapore 2009;38:600-5.

12. Surgical Treatment of Distal Radial Fractures with a Volar Locking Plate Versus Conventional Percutaneous Methods A Randomized Controlled Trial Alexia Karantana, Nicholas D. Downing, Daren P. Forward, DM, Mark Hatton, FRCS(Orth), Andrew M. Taylor, Brigitte E. Scammell, Chris G. Moran, and Tim R.C. Davis. J Bone Joint Surg Am. 2013;95:1737-44
13. Axelrod TS, McMurtry RY. Open reduction and internal fixation of comminuted, intraarticular fractures of the distal radius. $\mathbf{J}$ Hand Surg [Am]. 1990;15:1-11.

14. Knirk JL, Jupiter JB. Intra-articular fractures of the distal end of the radius in young adults. J Bone Joint Surg Am. 1986;68:647-59

15. Missakian ML, Cooney WP, Amadio PC,Glidewell HL. Open reduction and internal fixation for distal radius fractures. $\mathbf{J}$ Hand Surg [Am]. 1992;17:745-55

16. Bradway JK, Amadio PC, Cooney WP. Open reduction and internal fixation of displaced, comminuted intra-articular fractures of the distal end of the radius. $\mathrm{J}$ Bone Joint Surg Am. 1989;71:839-47

17. Trumble TE, Schmitt SR, Vedder NB.Factors affecting functional outcome of displaced intra-articular distal radius fractures. J Hand Surg [Am]. 1994;19:32540.

18. Leung KS, Shen WY, Tsang HK, Chiu KH, Leung PC, Hung LK. An effective treatment of comminuted fractures of the distal radius. J Hand Surg [Am]. 1990;15:11-7.

19. Kogsholm J, Olerud C. Plaster cast Vs External fixation for unstable intra articular Colles fractures. Clin Orthop $1989 ; 241$ : 57.

20. Bartosh RA, Saldana MJ. Intraarticular fractures of the distal radius: a cadaveric study to determine if ligamentotaxis restores radiopalmar tilt. J Hand Surg [Am]. 1990;15:18-21. 